\title{
EDUCAÇÃo POPULAR COMO TEORIA E PRÁTICA DA EDUCAÇÃo DO CAMPO: DIÁLOGOS COM PAULO FREIRE
}

\author{
POPULAR EDUCATION AS THE THEORY AND PRACTICE OF \\ COUNTRYSIDE EDUCATION: DIALOGUES WITH PAULO FREIRE
}

\begin{abstract}
Maria do Socorro Silva ${ }^{1}$
\section{RESUMO}

Este artigo emerge de uma pesquisa que realizamos durante o doutorado, a partir da análise documental das práticas que constituem o Movimento da Educação do Campo. Realizamos também com uma revisão de literatura sobre a contribuição de Paulo Freire e da Educação Popular para o Movimento Político-PedagógicoEpistêmico da Educação do Campo, que emerge no Brasil no final da década de 1990, como contraposição ao projeto societário hegemônico e ao modelo de Educação Rural. Para tanto, explicitamos inicialmente o conceito de Educação Popular (EP) que adotamos, considerando-a como uma teoria e prática da educação e como matriz fundamental para a implementação das práticas educativas escolares e não escolares do campo. Em seguida, discutimos como os movimentos educativos populares e as organizações da classe camponesa se constituíram como sementeiras da Educação do Campo. Por fim, apresentamos a emergência da Educação do Campo como paradigma, movimento de luta, conjunto de práticas educativas e de políticas educacionais num diálogo com Paulo Freire.
\end{abstract}

Palavras-chave: Movimento da Educação do Campo; Educação Popular; Paulo Freire; Movimentos Sociais e Sindicais.

\begin{abstract}
This article emerges from research conducted during our doctorate program, based on the documentary analysis of Countryside Education Movement practices. We also carried out a literature review on Paulo Freire and Popular Education's contribution to the Political-Pedagogical-Epistemic Movement of Countryside Education, which emerged in Brazil at the end of 1990s, as a contrast to the hegemonic corporate project and the model of Rural Education. To do so, we initially explain the concept of Education Popular (EP) that we have adopted, considering it as a theory and practice of education and as a fundamental matrix for implementing school-based and non-school-based educational practices in the countryside. Then, we discuss how grassroots educational movements and peasant organizations seeded Countryside Education. Finally, we present the emergence of Countryside Education as a paradigm, social struggle movement, and a set of educational practices and policies in dialogue with Paulo Freire.
\end{abstract}

Keywords: Countryside Education Movement; Popular Education; Paulo Freire; Social and Trade Union Movements.

\footnotetext{
${ }^{1}$ Professora da Universidade Federal de Campina Grande, na Unidade Acadêmica de Educação do Campo. Doutora em Educação pela Universidade Federal de Pernambuco. e-mail: maria.socorro@ professor.ufcg.edu.br
} 


\section{Revista \\ Debates Insubmissos}

\section{INTRODUÇÃO}

O movimento para a liberdade deve surgir e partir dos próprios oprimidos, e a pedagogia decorrente será aquela que tem que ser forjada com ele e não para ele, enquanto homens ou povos, na luta incessante de recuperação de sua humanidade. Vê-se que não é suficiente que o oprimido tenha consciência crítica da opressão, mas, que se disponha a transformar essa realidade; trata-se de um trabalho de conscientização e politização. (FREIRE).

O presente trabalho constitui-se como um recorte de uma pesquisa que realizamos durante o doutorado ${ }^{2}$, reescrito a partir de diálogos com os desafios postos para as políticas da Educação do Campo no cenário atual. Este texto, tem, portanto, como objetivo, a explicitação da concepção que adotamos de Educação Popular (EP), enquanto teoria e prática da educação que toma a realidade social como conteúdo pedagógico a serviço da emancipação humana e da transformação das relações assimétricas existentes na sociedade. Assim, possibilitou identificar a influência dessa matriz pedagógica nos fundamentos e princípios das Propostas Pedagógicas das iniciativas da Educação do Campo.

Essa teoria da educação, que tem a metodologia dialética como dimensão epistemológica fundamental, possibilita uma reinvenção permanente dessas práticas, além da ênfase no caráter político que a escola assume na sociedade, principalmente no diálogo que estabelece com os movimentos sociais populares. Entendemos que essa contribuição advém das práticas educativas e dos educadores(as) latino-americanos(as) nos últimos 50 anos, especialmente da obra de Paulo Freire.

Não pretendemos fazer uma leitura histórica conceitual sobre Educação Popular, conforme podemos encontrar em outros estudos (MELO NETO, 1999, 2003; ROSAS, 2008, PALUDO, 2001), nos quais podemos compreender como a educação vai se institucionalizando nas diferentes formações sociais, ao longo da nossa história, e como a

\footnotetext{
${ }^{2}$ Este texto se originou da tese de doutorado desenvolvida no Núcleo de Pesquisa de Formação de Professores e Prática Pedagógica do Programa de Pós-Graduação do Centro de Educação da UFPE, que teve como objetivo compreender as práticas pedagógicas que se desenvolvem nas Escolas Básicas do Campo, que se filiam ao discurso político-pedagógico e epistemológico da Educação do Campo, posto em circulação por diferentes organizações sociais, principalmente a partir dos anos de 1990, no Brasil, sob orientação da Prof. Dra. Maria Eliete Santiago. Todavia, o texto aqui apresentado amplia a análise para refletir sobre questões posteriores a sistematização e defesa da tese.
} 
escola vai assumindo um caráter político, no qual se reproduzem ou se transformam as concepções de ser humano, sociedade e mundo, mas explicitar a concepção de Educação Popular que dialoga com as práticas educativas da Educação do Campo.

\title{
2. EDUCAÇÃO POPULAR COMO TEORIA E PRÁTICA DA EDUCAÇÃO
}

O poder da obra de Paulo Freire não está tanto na sua teoria do conhecimento, mas no fato de ter insistido na ideia de que é possível, urgente e necessário, mudar a ordem das coisas. A Educação é entendida como prática social que tem o objetivo de contribuir, direta e intencionalmente, no processo de construção histórica das pessoas, na formação da humanidade, na formação para o trabalho e para a cidadania. Trata-se, portanto, de educar as pessoas como sujeitos históricos e coletivos $^{3}$, na perspectiva de que se tornem autores sociais $^{4}$, sujeitos da construção de uma nova sociabilidade e de uma escola contextualizada na cultura e no trabalho.

O processo de inacabamento e inconclusão do ser humano faz com que as experiências ao longo da vida os tornem humanos ou desumanos. Essa visão de Paulo Freire (1978) sobre a aprendizagem da humanidade como um fazer permanente é fundamental. A educação pode ajudar a transformar o homem e a mulher em sujeitos da História. Não qualquer tipo de educação, mas uma educação crítica e dirigida à tomada de decisões e à intervenção social e política, manifestando uma concepção de Educação na qual:

\begin{abstract}
Os homens são vistos como seres históricos e, portanto, inacabados: na verdade, diferentemente dos outros animais, que são apenas inacabados, mas não são históricos, os homens se sabem inacabados. Têm a consciência de sua inconclusão. Aí se encontram as raízes da educação mesma, como manifestação exclusivamente humana. Isto é, na inconclusão dos homens e na consciência que dela têm. Daí que seja a educação um que fazer permanente. (FREIRE, 1978, p. 73).
\end{abstract}

\footnotetext{
${ }^{3}$ Os sujeitos sociais lutam pelas transformações do cotidiano, das inter/subjetividades. Os sujeitos coletivos, históricos, absorvendo as lutas sociais se organizam pelas transformações das conjunturas e das estruturas em função de uma maior participação social e pessoal, pela afirmação da dignidade de todos, homens e mulheres de diferentes etnias, idades, condições sociais, opções sexuais, e culturais, em novas relações de poder numa institucionalidade estatal ressignificada. (SOUZA, 2006).

${ }^{4}$ Adotamos a definição de João Francisco de Souza (2006) de autores sociais como gestores de seus processos sociais, participantes do processo social do conjunto da sociedade, fazedores da história e de sua própria história.
} 
A inconclusão do ser humano suscita que a prática educativa busque cotidianamente sua própria mudança, considerando a diversidade dos processos de socialização do ser humano, a partir da interação com a cultura, pelas formas de organização do trabalho, pelas interações que conformam sua subjetividade e sua linguagem. Assim, "esta transformação, só tem sentido na medida em que contribuir para a humanização do homem. Na medida em que se inscrever na direção de sua libertação" (FREIRE, 1987, p. 130).

Para João Francisco de Souza (2000), o processo de humanização requer uma ressocialização dos seres humanos, implicando transformações de nossas formas de pensar, de fazer, de sentir. Essa ressocialização se dá por dois processos. Primeiro, dá-se pela recognição, que são as mudanças nas nossas formas de pensar, de compreender a nós mesmos, aos outros, a natureza, a cultura, as instituições sociais, enfim, de ressignificar o mundo, possibilitando a desconstrução de ideias anteriores e a construção de outra compreensão dos assuntos e problemas. O outro processo pelo qual se dá a ressocialização é a reinvenção, ou seja, as mudanças nas emoções, nas formas de agir, de se organizar, no gosto de viver e conviver.

Uma educação para a humanização, portanto, supõe a promoção de um processo educativo que possibilita ao sujeito se constituir enquanto ser social crítico, autônomo e criativo; capaz de refletir sobre seu trabalho e seu mundo. Consequentemente, demanda uma ação cultural, de construções pessoais, interativas e sociais do modo de ser, de viver, de pensar, sentir e agir dentro dos limites e possibilidades da sociedade em que se encontra. Como salienta Paulo Freire (1978, p. 78)

A educação libertadora, problematizadora, já não pode ser o ato de depositar e narrar, ou de transmitir "conhecimentos" e valores aos educandos, meros pacientes à maneira da educação "bancária", mas um "ato cognoscente". [...] Educação problematizadora consiste de caráter autenticamente reflexivo, implica num constate ato de desvelamento da realidade.

Nesse sentido, a educação é um processo que permite ao ser humano a produção de si mesmo, na medida em que estão presentes a mediação e a interação com o outro e com o mundo, possibilitando a construção da pessoa humana enquanto ser social e singular. Para Alder Júlio Calado (2000), deve-se associar e articular a realidade social para além das 


\section{Revista \\ Debates Insubmissos}

leituras científicas do mundo, dialogando com o que forma o ser humano, suas subjetividades, seus desejos e inteligências, numa relação entre "saber/sabor/sabedoria". Para isso, conhecimentos e saberes são utilizados como elementos construtores da humanidade, ao mesmo tempo em que são construídos por ela, a partir de diferentes instituições, processos culturais, sociais e educativos, escolares e não escolares ${ }^{5}$.

Assim, a EP se efetiva a partir das dimensões do processo educativo, como uma opção que:

[...] surge da conjunção dialética de vários fatores sociais (econômicos-ideológicos) e pedagógicos inserida na práxis cotidiana de sujeitos coletivos e da escolarização popular. A Educação Popular se compreende como dinamizadora do aspecto organizativo pelo potenciamento da dimensão educativa própria não só das ações sociais, mas também do processo didático escolar. (SOUZA, 2004, p. 169).

A necessidade de uma coexistência entre essas dimensões da Educação é enfatizada no sentido de que a expansão do campo da educação não escolar, que abarca a educação "não formal e informal" e que, historicamente, coexiste com a educação escolar, - requer uma maior integração e complementaridade das práticas educativas destas diversas áreas, considerando o desafio do acesso à produção de conhecimentos na sociedade atual. ${ }^{6}$

Essa concepção ampla de Educação foi se constituindo na América Latina e no Brasil no final do século XIX, e se firmou no século XX, conjuntamente com a adjetivação de popular. Ocorreu principalmente a partir dos anos de 1960 e se expandiu a partir dos anos de 1980, delimitando sua singularidade de história e princípios:

\footnotetext{
${ }^{5}$ A terminologia formal/não formal/informal, de origem anglo-saxônica, introduzida a partir dos anos de 1960, é popularizada a partir da Conferência sobre a Crise Mundial da Educação (1967), organizada pela UNESCO sob a direção de P. H. Coombs. Esta partição do universo educativo, bem como a sua delimitação terminológica, assim configurada desde a referida Conferência, prolonga-se até os dias de hoje - não de forma exclusiva ou consensual, mas ainda assim abundantemente referenciada, quer no âmbito acadêmico, quer nos domínios políticos ou especificamente educativos.

${ }^{6}$ Embora historicamente o termo educação não formal esteja sendo utilizado para nomear práticas fora do âmbito das escolas, essa nomeação pode constituir um importante limitador para a análise das inúmeras iniciativas de educação do campo e sua relação com o complexo contexto atual, visto que muitas dessas práticas ocorrem como complementares a educação escolar. Portanto, neste trabalho utilizaremos os termos escolar e não escolar para nos referirmos aos processos educativos desenvolvidos pela escola, e os que são realizados por outras instituições.
} 


\section{Revista \\ Debates Insubmissos}

A conotação popular converge na direção que identifica a opção filosófica, política, econômica, cultural de estar em sociedade como opção conscientemente crítica. Emerge como educação popular pelo princípio de emancipação e propaga-se como projeto social em defesa da libertação humana (ROSAS, 2008, p. 102).

Essa denominação de popular se constitui como resultante dos processos socioculturais e políticos das lutas das organizações populares, como expressão da resistência às estruturas de dominação e, principalmente, das diferentes práticas educativas desenvolvidas em diferentes lugares: "suas características de resistência e confronto advêm da vida cotidiana, do trabalho campesino e posteriormente urbano, da experiência com produção artesanal à industrial. Nasce na oralidade e ganha maturidade na escrita e emprego de novas tecnologias" (ROSAS, 2008, p. 103).

Na constituição desse conceito nos deparamos, segundo Alder Júlio Calado (2000, p.14), com "uma tensão dialética entre as forças hegemônicas e suas estratégias de dominação de um lado, e, do outro, as diferentes manifestações de protagonismo dos Movimentos Sociais Populares". Isso leva a refletir sobre o que vem sendo entendido como popular. Embora o conceito tenha apresentado diferentes significados, a partir do projeto de modernidade o popular vem sempre vinculado ao termo povo, muitas vezes entendido genericamente como cidadãos ou população. Contudo, dentro do debate do campo popular, esse conceito assume outra compreensão.

Segundo Oscar Jara (2009), o termo "Povo" é compreendido dentro de duas perspectivas: de "povo social", como os que sofrem na sociedade as assimetrias de qualquer tipo: opressão, discriminação, exclusão, inclusão perversa, exploração, espoliação; e a de "povo político", na dimensão de classe popular, no momento que se articulam, se organizam e se põem em movimento contra a interdição, a opressão e a segregação porque sabem ser segregados - e possuem, como diz Paulo Freire (1978), potencial de (re)fundação social.

A discussão sobre o popular e sua vinculação com a educação leva também a uma reflexão sobre as classes populares ${ }^{7}$, os movimentos sociais e a constituição do Campo Popular, que, para Conceição Paludo (2009), são forças políticas e culturais contra

\footnotetext{
${ }^{7}$ Na conceituação de Wanderley (1987), classes populares, no plural, compreende o operariado industrial, os trabalhadores em geral, os desempregados, os indígenas, o campesinato, os funcionários públicos.
} 
hegemônicas que se articulam, conformando campos sociais, que guardam relação com a esfera da economia, possuem "visões sociais de mundo" e orientam sua teorização sobre a realidade e suas ações numa perspectiva de transformação social.

João Francisco de Souza (2000, p. 75) vincula o popular aos movimentos sociais, que expressam correntes de opiniões capazes de firmar interesses contrários aos dominantes. $\mathrm{O}$ autor conceitua os movimentos sociais como:

grupos de pessoas com posicionamentos políticos e cognitivos similares, que se sentem parte de um conjunto, além de se perceberem como força social capaz de formar interesses frente a posicionamentos contrários de outros grupos. Pessoas que agem, afirmam posições e se sentem vinculadas. Expressam-se como correntes de opiniões sobre diversos campos da existência individual e coletiva, sobretudo dos segmentos sociais explorados, oprimidos e subordinados que passam a competir no mercado das ideias e no sentimento de pertenças (...) são força social atuante que se manifesta através de organizações e grupos de diversas e divergentes naturezas, amplitude e vigor.

Portanto, os movimentos sociais começam a ser entendidos também como práticas sociopolíticas e culturais da sociedade civil que visam a realização de seus projetos por uma vida melhor (SCHERRER-WARREN, 1998). Por conseguinte, sujeitos coletivos que se articulam a partir de identidades sociais e coletivas, na luta pelo reconhecimento de seus direitos e pela afirmação de sua cidadania.

Nessa perspectiva, "Povo", longe de significar uma homogeneização social, significa a diversidade dos explorados e interditados dentro de uma formação social. Na dimensão social e política, utilizaremos o termo "Povos do Campo" para nos referirmos aos que produzem e reproduzem sua vida numa relação direta com a terra, a floresta e as águas, e sofrem algum tipo de assimetria e opressão no campo brasileiro.

Para Oscar Jara (2009), o popular faz referência a um processo que busca superar as relações de domínio, de opressão, de discriminação, "que busca construir relações equitativas, justas, respeitosas da diversidade e da igualdade de direitos na busca do desenvolvimento pleno de todas as capacidades humanas" (p. 236).

Dessa forma, a construção da Educação Popular no Brasil, inclusive conceitualmente, será marcada pelas contradições dos processos sociais e históricos e, principalmente, pela 
ressignificação que ocorre no denominado Campo Popular, no que se refere ao papel dos movimentos sociais populares dentro da sociedade, na sua relação com o Estado e nas finalidades da Educação para o fortalecimento do protagonismo das classes populares dentro de cada contexto histórico.

A partir destes princípios, adotamos o conceito de Educação Popular, conforme posta por Paulo Freire (1995, p. 101-102), como sendo aquela educação que:

a) substantivamente democrática não separa do ensino dos conteúdos o desvelamento da realidade; b) estimula a presença organizada das classes populares... no sentido da superação das injustiças sociais; c) respeita os educandos... e por isso mesmo leva em consideração seu saber de experiência feito, a partir do qual trabalha o conhecimento com o rigor de aproximação dos objetos; d) trabalha, incansavelmente, a boa qualidade do ensino; e) capacita suas professoras cientificamente à luz dos recentes achados em torno da aquisição da linguagem, do ensino da escrita e da leitura; f) em lugar de negar a importância da presença dos pais, da comunidade, dos movimentos populares na escola, se aproxima dessas forças com as quais aprende para a elas ensinar também; g)supera preconceitos de raça, de classe, de sexo e se radicaliza na defesa da substantividade democrática; ao realizar-se assim, como prática eminentemente política, tão política quanto a que oculta, nem por isso transforma a escola onde se processo em sindicato ou partido.

Portanto, Educação Popular, organiza e vivencia o conteúdo na perspectiva da formação humana, de apropriação e ampliação dos saberes, a serviço da transformação das relações assimétricas existentes na sociedade e, para isso, reorganiza o trabalho escolar numa perspectiva de construir sujeitos críticos, criativos e participativos dentro e fora do espaço escolar.

\section{OS MOVIMENTOS EDUCATIVOS POPULARES E AS ORGANIZAÇÕES CAMPONESAS: AS SEMENTEIRAS DA EDUCAÇÃO POPULAR}

A teoria e prática da Educação Popular teve nos movimentos de cultura popular e de educação de adultos instrumentos de transformação social e conscientização dos trabalhadores enquanto classe social e em Paulo Freire o seu principal referencial. O processo de formulação da concepção da Educação Popular começa no início dos anos de 1960, tecido inicialmente fora dos muros escolares, a partir da constituição dos Movimentos Educativos 


\section{Revista \\ Debates Insubmissos}

Populares, que serão precursores de uma visão crítica da escola e da educação intercultural no Brasil (CARVALHO, 2004).

O marco dessa redefinição foi o II Congresso Nacional de Educação de Adultos, realizado em julho de 1958, no Rio de Janeiro, que tinha como uma de suas finalidades uma avaliação por parte dos profissionais da educação do que estava acontecendo no país com relação à educação de adultos, visando o seu aperfeiçoamento.

A multiplicidade de posições ideológicas defendidas pelos participantes começa a se expressar a partir dos Seminários Regionais Preparatórios, quando começam a surgir novas ideias da educação de adultos como instrumento de transformação social, cuja proposta foi configurada no Seminário Regional de Pernambuco, pois, conforme o documento ${ }^{8}$ :

A “sociabilidade" intrínseca ao processo educativo, que não o permite reduzir-se a um simples processo intelectual, exige dele uma concordância com o contorno histórico-social da sociedade a que se pretende aplicar. (...) Conhecida, tão criticamente quanto possível esta realidade, em mudança constante, passará o processo educativo a trabalhá-la. (...), é fator também de mudança enquanto pode criar novas disposições mentais no homem, capazes de inseri-lo melhor na contextura histórico-cultural. Novas disposições mentais que lhe deem, sobretudo, a possibilidade de melhor compreender a sua situação neste contexto. (FREIRE, 1958, p. 2).

A educação de adultos é uma referência para a constituição dos movimentos pedagógicos que vão se estruturar a partir de então. De acordo com Vanilda Paiva (1985, p. 210-211), esse Congresso marca:

O início da transformação do pensamento pedagógico brasileiro, com o abandono do “otimismo pedagógico" e a reintrodução da reflexão social na elaboração das ideias pedagógicas. Além disso, ele serviu também como estímulo ao desenvolvimento de ideias e novos métodos educativos para adultos. (...) nele predominou a posição do grupo mais favorável à participação política, através das bases eleitorais e à aceitação de que os problemas brasileiros se resolveriam através do aceleramento do processo de desenvolvimento e da mudança social que deveria acompanhá-lo.

\footnotetext{
${ }^{8}$ Nesse Seminário foi organizado um documento por uma pequena equipe da qual participava Paulo Freire, que apresentou o documento intitulado "A Educação de Adultos e as Populações Marginais: mocambos", chamando a atenção para as causas sociais do analfabetismo e a importância de sua eliminação. Observa que, para isso, se faz necessário partir do contexto no qual se realiza o processo educativo.
} 
Essa teoria da educação, que tem a metodologia dialética como dimensão epistemológica fundamental, possibilita uma reinvenção permanente dessas práticas, além da ênfase no caráter político que a escola assume na sociedade, principalmente no diálogo que estabelece com os movimentos sociais populares. Entendemos que essa contribuição advém das práticas educativas e dos educadores(as) latino-americanos(as) nos últimos 60 anos, especialmente da obra de Paulo Freire.

Esses movimentos sociais populares defendiam que a educação dos setores populares deveria ser pautada por uma perspectiva emancipatória e que, compreendida como algo fundamental nas estratégias de luta para a sobrevivência e libertação desses setores, não poderia prescindir do protagonismo popular na sua própria formação (SILVA, 2006, p. 7).

\begin{abstract}
A contribuição dos movimentos educativos populares tecida inicialmente fora dos muros escolares, como movimentos de Cultura Popular, nos Círculos de Cultura, como uma ação cultural, na "periferia", nas praças, nas associações de moradores, essas iniciativas devem ser compreendidas também como estratégias de luta para a sobrevivência e libertação das camadas populares, que vão influenciar o surgimento de diversos movimentos de Educação Popular (Centro Popular de Cultura, Movimento de Cultura Popular, Movimento de Educação de Base, De Pé no Chão também se aprende a ler; e movimentos da ação católica ${ }^{9}$ (JAC, JEC, JIC, JOC, JUC), na proposta da Pedagogia da Alternância, que se desenvolvia no país desde o final dos anos de 1960 e no surgimento das primeiras organizações camponesas (Ligas Camponesas, ULTAB, MASTER).
\end{abstract}

A existência das Ligas Camponesas, da ULTAB, do Master e a influência do PCB e da Ação Popular - AP, fizeram com que a organização dos trabalhadores(as) rurais nas ligas camponesas e nos sindicatos fosse acelerada, as bandeiras de lutas atualizadas e ampliadas e estabelecidas linhas de ação comum. O processo de articulação entre essas três organizações em torno de lutas comuns, apesar das diferentes correntes de pensamento existentes em cada uma delas, culminou com o Congresso Nacional para criação da Confederação, o que ocorreu em 22 de dezembro de 1963, com a participação de trabalhadores rurais de 18 estados.

Nesse contexto, a CONTAG torna-se a primeira entidade sindical camponesa de caráter nacional. Ajustou em seu interior diversas concepções e correntes de pensamentos,

\footnotetext{
${ }^{9}$ Esses movimentos articulavam a juventude e se denominavam, respectivamente: Juventude Agrária Católica, Juventude Estudantil Católica, Juventude Independente Católica, Juventude Operária Católica e Juventude Universitária Católica. (SILVA, 2006).
} 
com setores da Igreja, lideranças provenientes das Ligas e os comunistas. Essa fase inicial de sua existência foi curta, pois logo em seguida vem o golpe militar, as lideranças são presas e torturadas, e são nomeados pelo regime interventores para assumirem os sindicatos, as federações e a confederação, situação que começa a se modificar no início da década de 1980, com a retomada do sindicalismo por novas lideranças e concepção sindical. (CONTAG, 2000).

Essas diferentes iniciativas políticas e educativas vão ser o celeiro para a formulação de uma nova concepção de Educação Popular, reforçando a afirmação de João Francisco de Souza (1999), no sentido de que os movimentos sociais populares que surgiram neste período representam um encontro cultural entre intelectuais e populares, à medida que são resultado dos processos de dominação existentes na sociedade e da organização de grupos de reflexão, da ação cultural, de ajuda mútua, de reinvindicação, construindo, assim, uma concepção que é política e pedagógica da Educação Popular, como uma prática educativa vinculada aos movimentos sociais na perspectiva da transformação social.

O golpe de 1964, que implantou o Estado da força e da repressão institucionalizada, violentou a concepção de educação que vinha se desenhando no Brasil a partir das diferentes iniciativas pedagógicas e políticas organizadas pela sociedade civil, com o fechamento dos canais de participação e representação, impondo limites e controle ao acesso dos segmentos populares aos bens educacionais e sociais. Educadores(as) comprometidos(as) e lideranças foram perseguidos e exilados, as Universidades sofreram intervenções e os movimentos populares foram desarticulados e extintos.

Para a ditadura, as organizações e movimentos de Educação Popular representavam "um perigo para a estabilidade do regime, para a preservação da ordem capitalista" (PAIVA, 1985, p. 259). Nesse sentido, desencadearam-se forte repressão sobre as organizações populares, movimentos de Educação Popular, de intelectuais e estudantes, deixando-se de lado durante os dois primeiros anos do governo militar qualquer iniciativa no campo da educação de adultos. As ações de alfabetização começam a ser retomadas apenas em 1966, a 


\section{noviste

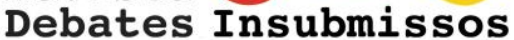

partir da pressão exercida pela UNESCO, com relação ao problema do analfabetismo e suas implicações para o desenvolvimento do país.

O contexto político da ditadura militar, marcado pela forte repressão contra os educadores(as) populares, as organizações políticas e, especificamente, as organizações camponesas, aliado a concepção tecnicista que se instala na educação e um pessimismo pedagógico, resultado de certa leitura das teorias da reprodução ${ }^{10}$, fazem com que as iniciativas de resistência à ditadura militar, com formação de grupos de educação de adultos, de formação sindical e popular, ocorram principalmente a partir da Igreja Católica, que seguiam a Teologia da Libertação e dos Centros de Assessoria Popular ${ }^{11}$.

Desse processo surgem as Comunidades Eclesiais de Base (CEBs) e as diversas pastorais, sempre ligadas aos grupos sociais minoritários, a saber: Conselho Indigenista Missionário, Pastoral do Menor, da Mulher Marginalizada, da Criança, da Juventude, Migrantes, dentre as quais destacamos a Comissão Pastoral da Terra (CPT), que iniciou seu trabalho pastoral em 1975, na organização dos camponeses para resistir na terra e lutar pela Reforma Agrária, e que tiveram uma atuação muito marcante nas regiões nordeste, norte e centro oeste do Brasil. O trabalho comunitário e de pequenos grupos foi a estratégia adotada durante muitos anos para resistir e formar novas lideranças camponesas, que vão ser fundamentais para a retomada do sindicalismo rural e a constituição dos movimentos de luta pela terra, dentre estes o Movimento dos Trabalhadores Sem Terra.

A Educação Popular buscou novos caminhos, atuando às margens das práticas oficiais implementadas pelo governo militar e, com isso, desenvolveu também um sistema alternativo e paralelo ao Estado, centrado principalmente na Educação de Adultos. Nesse período, esses

\footnotetext{
${ }^{10}$ As teorias da reprodução em educação (Althusser, Bourdieu e Passeron) ganharam nos espaços educativos uma leitura superficial e restrita a alguns conceitos, o que levou muitos educadores(as) a não apostarem na escola enquanto um espaço de construção de um sujeito crítico e transformador.

${ }^{11}$ A redemocratização da sociedade, a partir dos anos de 1980, coloca do ponto de vista organizativo outro elemento que é o surgimento dos Centros de Educação Popular, ou entidades de apoio, constituídos em sua maioria por militantes cristãos, estudantes, intelectuais, que buscaram resgatar a concepção de Educação Popular gestada nos trabalhos da década anterior, com a finalidade de assessorar o movimento sindical e popular que começava a se rearticular no país.
} 


\section{Revista \\ Debates Insubmissos}

movimentos buscavam autonomia perante o Estado autoritário (1964-1985), marcado fortemente pela centralização das decisões e dos recursos financeiros, negando-se as relações clientelistas e de tutela.

A Educação Popular que, nas décadas de 1960 e 1970, era tida como a prática que se desenvolvia na educação não formal, especialmente, com adultos, concepção aprofundada pela leitura da obra de Althusser de que a escola seria espaço de reprodução da ideologia do sistema, em função do controle que o Estado exercia sobre ela e seus agentes.

A década de 1980, marcada pelo processo de democratização da sociedade, coloca a escola como espaço de confronto e de disputa de interesses. A visão da prática educativa, contribuindo para a resistência e a transformação, suscita o debate da escola como espaço fundamental de proposição e prática da Educação Popular.

O ponto de partida deve ser exatamente a crítica ao projeto educativo imposto pelo interesse ideológico dominante, a contraposição a esse projeto e a configuração de uma escola com os princípios e fundamentos da Educação Popular, transformando sujeitos que poderão fazer opções humanas fundadas na autonomia, na liberdade, na democracia, na construção de conhecimentos que favoreçam o seu engajamento nas ações e organizações de emancipação da sociedade. Ou como nos coloca Conceição Paludo (2001, p. 76):

Situar a escola perpassada pela luta de classe remete a Gramsci e para além das teorias sociológicas funcionalistas e crítico-reprodutivistas das relações entre escolasociedade, fazendo compreender que a educação é uma prática social que está inserida num contexto global, mas construída cotidianamente por pessoas concretas, com as leis e apesar das leis. Isto é a educação como prática social instituída, é um espaço importante de disputa de hegemonia, de produção individual e coletiva de significados e práticas que podem indicar para além da promoção de oportunidades individuais de melhoria de vida para alguns, apontando na direção da articulação da construção do saber escolar com a cultura 'desinteressada' e não discriminatória; com a economia (trabalho formal, informal e autônomo) e com a política, concretizando no cotidiano a formação do homem omnilateral e de uma concepção de mundo.

Nessa mesma direção reflete Eliete Santiago (1990, p. 27), quando coloca que a escola:

não se restringe ao estritamente escolar. Não se limita à abordagem interna da educação, mas estando integrada à finalidade social mais ampla, a de servir como um 
dos instrumentos úteis a transformação estrutural da sociedade, ao permitir que os filhos dos trabalhadores elaborem, ampliem, se apropriem e usem o conhecimento que lhes permitirá o acesso e o trânsito na sociedade, compreendendo-a.

A década de 1980, será de renovação do movimento sindical rural, e também de surgimento de um combativo movimento social do campo, o Movimento dos Trabalhadores Sem-Terra (MST), que nasce colocando a necessidade que o saber e sabedoria do campo esteja presente na escola, e que esta seja espaço também de formar as lideranças, de preparar para a vida, para a organização e transmitir os conhecimentos acumulados historicamente pela humanidade.

A retomada das lutas pela terra e pela reforma agrária foram gerando mudanças no campo brasileiro, camponesas e camponeses retomaram a luta histórica pelo acesso e permanência na terra, e uma visão do campo como lugar de vida, de cultura, de trabalho e de direitos. Neste sentido, a contraposição ao modelo de educação rural, como um projeto criado para a população rural numa perspectiva de sua adaptação a modernização conservadora capitalista passa a ser profundamente questionado, inclusive no que se refere a sua prática precária, com poucos recursos, com pouca qualidade e descontextualizada da realidade camponesa.

É nessa perspectiva da denúncia do modelo hegemônico e no anúncio a uma proposta alternativa que as lutas dos movimentos sociais e sindicais camponeses começam a incorporar em sua agenda a escola pública como fundamental, apostando conforme a análise de Paulo Freire (1997), que a escola não é só um lugar para estudar, ela é um lugar de formação política, de convivência, de participação e de busca por transformação social.

\section{O MOVIMENTO DA EDUCAÇÃO DO CAMPO: ENRAIZADO NA EDUCAÇÃO POPULAR E NOS MOVIMENTOS SOCIAIS E SINDICAIS CAMPONESES}

O Movimento Nacional de Educação do Campo, que nasce no final dos anos de 1990, estrutura-se a partir de uma rede política composta por movimentos sociais e sindicais, organizações sociais e universidades que desenvolviam ações formativas com a população camponesa. Esse processo aconteceu com a participação de diferentes entidades, dentre as 


\section{Revista \\ Debates Insubmissos}

quais podemos destacar: Movimento dos Trabalhadores Sem Terra (MST), da Confederação Nacional dos Trabalhadores (as) na Agricultura (CONTAG), da União Nacional das Escolas Famílias Agrícolas no Brasil (UNEFAB), da Associação Regional das Casas Familiares Rurais - (ARCAFAR), da Rede de Educação do Semiárido Brasileiro (RESAB), dentre outras que constituíram esta rede política, pedagógica e epistêmica da Educação do Campo.

A Educação do Campo nasceu tomando posição contra a lógica e o modelo de desenvolvimento gerador de assimetrias sociais, políticas e econômicas construídas historicamente no Brasil. O entendimento de que o campo comporta uma diversidade de agroecossistemas, etnias, culturas, relações sociais, padrões tecnológicos, formas de organização social e política, e da necessidade de fortalecer uma ruralidade pautada pela agricultura familiar/camponesa se contrapõe ao discurso hegemônico da modernização conservadora pela urbanização e modelo de campo pautado pelo agronegócio e hidronegócio na sua forma de exploração do trabalho e de depredação da natureza (SILVA, 2009).

O conceito de Educação do Campo, enquanto uma concepção e prática políticopedagógica, encontra-se em construção na última década, no contexto histórico das contradições da sociedade brasileira, no que se refere à relação entre campo e cidade no projeto de desenvolvimento e ao papel da escola neste processo, portanto, vem se constituindo numa territorialidade política e teórica de disputa para transformação da realidade.

A Educação do Campo é definida a partir de sujeitos: agricultores/as familiares, assalariados/as, posseiros, assentados/as, ribeirinhos, caiçaras, extrativistas, pescadores, artesanais, indígenas, remanescentes de quilombolas, comunidades de fundo de pasto gerazeiros, enfim, todos os Povos do Campo brasileiro. Essa concepção está expressa no art. $2,{ }^{\circ} \S$ único das diretrizes, quando diz que:

A identidade da escola do campo é definida pela sua vinculação às questões inerentes à sua realidade, ancorando-se na temporalidade e saberes próprios dos estudantes, na memória coletiva que sinaliza futuros, na rede de ciência e tecnologia disponível na sociedade e nos movimentos sociais em defesa de projetos que associem as soluções exigidas por essas questões à qualidade social da vida coletiva no país (CNE, 2002). 
Na dimensão política, o Movimento da Educação do Campo coloca os Povos do Campo como sujeitos de direitos, dentre os quais se evidencia a educação. A luta pelo direito ao acesso e a permanência na escola torna-se uma das reivindicações centrais das diferentes instituições e organizações sociais que constituem o Movimento da Educação do Campo. Mais do que um direito dos sujeitos do campo, e de afirmação da cidadania, a Educação se constitui enquanto processo de formação da humanidade do ser humano, numa perspectiva emancipadora, e de intervenção na realidade. Trata-se de um projeto educativo centrado no diálogo-libertador, que valoriza o empoderamento dos sujeitos, o seu pertencimento a uma classe social e a um contexto social de projetos societários em disputa.

Esse é um dos princípios para a Educação do Campo se enraizar a partir do diálogo com a Pedagogia do Oprimido (1978), e na tradição pedagógica decorrente das experiências da Educação Popular na América Latina, que incluem o diálogo com as matrizes pedagógicas da opressão (a dimensão educativa da própria condição de oprimido); da cultura (aprendizado de significar ou ressignificar suas ações, valores e comportamentos); do trabalho (na produção de bens, na mudança das relações com a natureza); da práxis (prática e teoria combinadas, conhecimento como compreensão da realidade para transformá-la); da convivência (do convívio solidário entre as pessoas e da interação crítica e transformadora entre elas e o contexto em que vivem); e na construção de coletividades (as pessoas aprendem a ser humanas na partilha de conhecimentos, de sentimentos e de ações com outros seres humanos).

A concepção da Educação do Movimento se referencia nos processos econômicos, sociais, políticos e culturais empreendidos pelos sujeitos sociais e coletivos do campo, que se constituem como formadores do ser humano, constituintes de um projeto de educação emancipatória, pautado por uma postura político-pedagógica crítica, dialética e dialógica que orienta as diferentes Propostas Pedagógicas do Movimento que evidenciam a materialidade de sua origem.

O I Encontro Nacional dosłas Educadoreslas da Reforma Agrária - I ENERA, foi um espaço fundamental para a articulação ao nível nacional das práticas que estavam sendo desenvolvidas nos assentamentos e acampamentos da Reforma Agrária, suscitando a 


\section{noviste

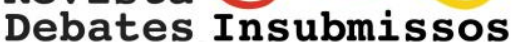

formulação do Programa Nacional de Educação na Reforma Agrária (Pronera), uma das primeiras conquistas e política deste movimento. O Pronera possibilitou um espaço fundamental para que os movimentos de luta pela terra, organizações não governamentais, universidades, poder público para a organização e realização de um evento nacional para discutir os projetos de campo, a educação da população camponesa e a presença ou ausência das políticas educacionais (ROCHA, 2013).

Com essa Articulação Nacional da Educação do Campo, se realizou, em 1998, em Luziânia, Goiás, a I Conferência Nacional da Educação do Campo - I CNEBC, espaço fundador do movimento nacional, e do próprio conceito de Educação do Campo, que processualmente passa a materializar seus princípios e fundamentos com as matrizes pedagógicas críticas, dentre as quais a Pedagogia do Oprimido.

$\mathrm{O}$ resgate desta matriz pedagógica se faz presente no processo de articulação do Movimento da Educação do Campo, conforme Documento Base da II Conferência Nacional da Educação do Campo, realizada em 2004, como indicamos em seguida:

A nossa caminhada se enraíza nos anos 60, quando movimentos sociais, sindicais e algumas pastorais passaram a desempenhar papel determinante na formação política de lideranças do campo e na luta pela reivindicação de direitos no acesso à terra, crédito diferenciado, saúde, educação, moradia, entre outras. Fomos então, construindo novas práticas pedagógicas através da educação popular que motivou o surgimento de diferentes movimentos de educação no e do campo, nos diversos estados do país. Mas foi na década de 80 / 90 que estes movimentos ganharam mais força e visibilidade. (II Conferência Nacional da Educação do Campo, 2004 ${ }^{12}$ ).

O documento desta II Conferência apresenta a defesa da Educação do Campo articulada a um "projeto popular de agricultura que valorize e transforme a agricultura familiar-camponesa", que ajude a superar a oposição hierarquizadora entre campo e cidade sustentada numa compreensão de que "progresso de um país se mede pela diminuição da sua

\footnotetext{
${ }^{12}$ Assinam a Declaração Final da II Conferência Nacional de Educação do Campo os seguintes Movimentos Sociais e Organizações, a saber: CNBB, MST, UNICEF, UNESCO, UnB, CONTAG, UNEFAB, UNDIME, MPA, MAB, MMC, MDA/INCRA/PRONERA, MEC, FEAB, CNTE, SINASEFE, ANDES, Comissão de Educação e Cultura da Câmara dos Deputados, Frente Parlamentar das CEFFAs, SEAP/PR, MTE, MMA, MinC, CONSED, FETRAF, CPT, CIMI, MEB, PJR, Cáritas, CERIS, MOC, RESAB, SERTA, IRPAA, Caatinga, ARCAFAR SUL/NORTE, ASSESSOAR, FÓRUM QUILOMBOLA (SILVA, 2009, p. 167).
} 


\section{novist

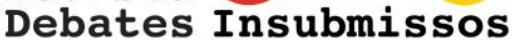

população rural" - e que contribua para a construção de um "projeto de desenvolvimento sustentável de campo e de país" (CNEC, 2004, p. 3)

A partir dos Movimentos Sociais e Sindicais a Educação do Campo faz o diálogo com a teoria pedagógica, considerando a especificidade e a diversidade dos contextos e práticas sociais dos Povos do Campo, e a preocupação com a educação do conjunto da população. Pois, conforme nos coloca Paulo Freire, "se o meu compromisso é realmente com o homem concreto, com a causa de sua humanização, de sua libertação, não posso por isso mesmo prescindir da ciência, nem da tecnologia, com as quais me vou instrumentando para melhor lutar por esta causa" (FREIRE, 2007, p. 22)

A Educação como emancipação humana compreende que os sujeitos possuem história, participam de lutas sociais, sonham, têm nomes, gêneros, etnias diferenciadas e que, ao lutar pelo direito à terra, à floresta, à água, à soberania alimentar, a matrizes tecnológicas com princípios agroecológicos, a estratégias de produção e comercialização solidárias, vão recriando suas pertenças, reconstruindo a sua identidade na relação com a natureza, com o trabalho e a cultura. Também vão superando de forma coletiva, situações de exploração e transformando a realidade na qual estão inseridos (as), numa perspectiva de integralidade, pois

[...] a realidade para nós é inteira, as distinções são criadas apenas para análise, para unir melhor; como dizia Jacques Maritain, distinguir para unir, jamais para separar as realidades. Todas as dimensões fazem parte do real, da vida, e os processos educativos são construídos levando em conta a interdimensionalidade, a integralidade, a omnilateralidade da formação (MOURA 2003, p. 86).

A formação humana integral tem como pressuposto na prática educativa a omnilateralidade do ser humano. Desse modo,

[...] a práxis educativa revolucionária deveria dar conta de reintegrar as diversas esferas da vida humana que o modo de produção capitalista prima por separar, ou seja, uma educação omnilateral, que trabalhe em suas práticas as várias dimensões da pessoa humana (DOSSIÊ MST ESCOLA, 2005, p. 163).

Nesta perspectiva, uma educação omnilateralidade pressupõe também o usufruto dos direitos civis, políticos e sociais, nos âmbitos individual e coletivo, o que se desdobra em 


\section{Revista \\ Debates Insubmissos}

questões morais, éticas e numa formação que contemple os sujeitos históricos como uma totalidade, portanto, uma educação

[...] como um processo sociocultural em que os sujeitos resgatam, constroem e ressignificam práticas, saberes e experiências numa perspectiva crítica e criativa de empoderamento do sujeito histórico e do coletivo, de construção e valorização integral dos seres humanos e de uma visão crítica do meio em que vivem (RESAB, 2007, p. 44).

Assim, a Educação precisa ser entendida como maior que a escola, pois está presente no trabalho, na família, na cultura, nas organizações sociais, etc. Embora a escola seja importante, ela é apenas um dos tempos e espaços da formação humana. Dessa forma,

Educação não é sinônimo de escola. Ela é muito mais ampla porque diz respeito à complexidade do processo de formação humana, que tem nas práticas sociais o principal ambiente dos aprendizados de ser humano. Mas a escolarização é um componente fundamental neste processo e um direito de todas as pessoas. (DOSSIÊ MST, 2005, p. 233).

A escola do e no campo assume um papel importante no acesso aos saberes científicos, porque as classes dominantes concentraram as terras, as riquezas e também os conhecimentos. Por isso, a classe trabalhadora sempre lutou para que suas filhas e filhos pudessem ter acesso a escolarização, tendo influência nos currículos, para que sua vida, seu trabalho, pudessem estar presentes nos currículos, na produção do conhecimento científico, nas universidades.

A contribuição de Paulo Freire para que possamos pensar de uma forma dialética a sociedade capitalista, com suas contradições, contribui para repensar a função da escola como um lugar de formação humana, de trabalho, de cultura, de ensino, de aprendizagem, de realizar uma leitura crítica da realidade, na perspectiva de questionar o que está posto numa posição de resistência a este cenário neoliberal.

Reconhecemos o papel que tem a escola para homens e mulheres, sabendo também que não será ela a única responsável pelas transformações da sociedade, pois vem orientada, muitas vezes, para a manutenção das estruturas sociais e econômicas dominantes, que impedem a própria transformação, pois aprendemos também com Paulo Freire que "a transformação da educação não pode antecipar-se à transformação da sociedade, mas esta transformação necessita da educação" (FREIRE, 1991, p. 84). 
Neste sentido a dialogicidade do pensamento freireano com a Educação do Campo comungam pela forma crítica com que tem se materializado nos diferentes territórios camponeses, e reinventado a teoria e a prática pedagógica. E, ao realizar com os Povos do Campo o debate sobre as políticas educacionais vinculados aos problemas vivenciados pela sociedade, a educação passa a ser compreendida como prática social importante para a intervenção nesta realidade.

\section{CONSIDERAÇÕES FINAIS}

A Educação do Campo que tem se constituído no Brasil, como um movimento de luta, um conjunto de práticas educativas e de políticas educacionais, possibilita um diálogo fecundo e potente entre teorias críticas da Educação, dentre as quais a Pedagogia do Oprimido, de Paulo Freire.

A retomada do protagonismo dos movimentos sociais e sindicais camponeses torna-se fundante para o fortalecimento das lutas sociais e educacionais que nos desafiam neste cenário econômico, político, cultural e sanitário que estamos vivendo no Brasil.

Num momento histórico em que o neoliberalismo e o conservadorismo acentuam na sociedade brasileira um desmonte das políticas sociais, na espoliação dos fundos públicos e na desregulamentação do trabalho, se instaura uma verdadeira cultura da morte, do desprezo a vida, uma "pedagogia da crueldade" que não se solidariza humanamente com nada e diz "e daí" para todas, todos e todes.

A Educação pública é atacada, tanto no campo como na cidade, esse desmonte se expressa na militarização das escolas e da sociedade, em projetos como a "Escola Sem Partido", na privatização da educação, com a parceria entre o empresariado - capital privado com o poder público, a proposta de "homeshooling" (escola doméstica), no congelamento de carreira e salários dos professores/as, na padronização e controle do currículo e do trabalho docente. 
A vinculação da Educação do Campo com o projeto societário da agricultura familiarlcamponesa, com a agroecologia, com a soberania alimentar, com a defesa das águas e sementes e contra o patriarcado e o racismo, se torna estratégico para reafirmar o papel de emancipação e transformação posta na Pedagogia Freireana para a educação e a escola, o que tem possibilitado para a Educação do Campo se constituir numa ferramenta de luta para a classe trabalhadora do campo, não simplesmente como uma modalidade de ensino.

Ou como diz Paulo Freire: "ir mais além do mero estar no mundo, acrescentam à vida que tem a existência que criam. Existir é, assim, um modo de vida que é próprio ao ser capaz de transformar, de produzir, de decidir, de criar, de recriar, de comunicar-se". (FREIRE,1981, p.53).

Nesta perspectiva Paulo Freire nos convida para fortalecer os princípios: da vida como ponto de partida e de chegada de qualquer prática social e educacional, a luta e a ética pela construção de uma educação libertadora, a amorosidade regida pelo diálogo aberto, a negação da neutralidade da educação, a estética de um trabalho pedagógico voltado para a emancipação humana e a transformação social.

\section{REFERÊNCIAS}

CALADO, Alder Julio. Movimentos Sociais e Cidadania: um enfoque multifacetado. $1^{\mathrm{a}}$ ed. João Pessoa. Editora Ideal, 2000.

CNE.MINISTÉRIO DA EDUCAÇÃO. Diretrizes Operacionais para a Educação Básica nas Escolas do Campo. CNE/CEB. Brasília, 20

CONFERÊNCIA NACIONAL DA EDUCAÇÃO DO CAMPO. Documento Base. LuziâniaGoias, 1998.

CONFERÊNCIA NACIONAL DA EDUCAÇÃO DO CAMPO. Documento Base. LuziâniaGoiás, 2004.

CONTAG. Educação para o Desenvolvimento Sustentável. Anais do IV Fórum Contag de Cooperação Técnica. Recife, 2000. 
DOSSIÊ MST ESCOLA. Documentos e Estudos 1990-2001. Caderno de Educação n 13. Edição Especial. ITERRA/MST. Rio Grande do Sul, 2005.

FONEC. Carta de Criação do Fórum Nacional de Educação do Campo. Brasília: FONEC, agosto de 2010.

FREIRE, Paulo. A educação de adultos e as populações marginais: mocambos. (Maio de 1958). 1958. Policopiado.

FREIRE, Paulo. Pedagogia do Oprimido. $5^{\text {a }}$ ed. Rio de Janeiro: Paz e Terra, 1978.

FREIRE, Paulo. Ação Cultural para a liberdade. $5^{\text {a }}$ ed. Rio de Janeiro: Paz e Terra, 1981.

FREIRE, Paulo. A sombra desta mangueira. São Paulo. Olho d’ Água, 1985.

FREIRE, Paulo. Educação como prática de liberdade. Rio de Janeiro. Paz e Terra, 1987.

FREIRE, Paulo. Poder local, participação popular e construção da cidadania. In: Fórum de Participação Popular nas Administrações Municipais, 1995. Policopiado.

FREIRE, Paulo. A Educação na Cidade. São Paulo: Cortez, 1991.

FREIRE, Paulo. Pedagogia da indignação: cartas pedagógicas a outros escritos. São Paulo: UNESP, 2000.

GRAMSCI, Antonio. Os intelectuais e a organização da cultura. 4. Ed. (v.48). Rio de Janeiro: Civilização Brasileira, 1982.

JARA, Oscar. Ressignifiquemos as Propostas e Práticas de Educação Popular perante os Desafios Históricos Contemporâneos. In: Educação Popular na América Latina: diálogos e perspectivas/Pedro Pontual, Timothy Ireland (orgs.). Brasília: Ministério da Educação: UNESCO, 2009.

MELO NETO. José Francisco. Extensão Universitária, Autogestão e Educação Popular. João Pessoa: Editora Universitária/UFPB, 2004.

MOURA, Abdalaziz de. Princípios e Fundamentos da Proposta Educacional de Apoio ao Desenvolvimento Sustentável - PEADS: uma proposta que revoluciona o papel escola diante das pessoas, da sociedade e do mundo. Glória de Goitá-PE: SERTA, 2003.

PALUDO, Conceição. Educação Popular em busca de alternativas: uma leitura desde o Campo Democrático e Popular. Porto Alegre: Tomo Editorial \& Camp, 2001. 
PALUDO, Conceição. Educação Popular - Dialogando com Redes Latino-Americanas (2002-2003). In: Educação Popular na América Latina: diálogos e perspectivas/Pedro Pontual, Timothy Ireland (orgs.) - Brasília: Ministério da Educação: UNESCO, 2009.

RESAB. Educação para a Convivência com o Semi-Árido: reflexões teórico-prática. Juazeiro. Secretaria Executiva da Rede de Educação do Semi-árido Brasileiro, 2004.

RESAB. Educação para a convivência com o semiárido: Juazeiro: Secretaria Executiva da Rede de Educação do Semiárido Brasileiro, 2005.

ROCHA, Eliene Novaes. Das práticas educativas às Políticas Públicas: tramas e artimanhas pela Educação do Campo. Brasília: Pós-Graduação em Educação da Faculdade de Educação da Universidade de Brasília/UnB, 2013.

ROSAS, Agostinho da Silva. Paulo Freire: a Criatividade em Educação Popular. Tese. (Doutorado em Educação). João Pessoa: UFPB, 2008.

SANTIAGO, Eliete. Escolas Públicas de $1^{\circ}$ grau :da compreensão à intervenção/Maria Eliete Santiago. Rio de Janeiro: Paz e Terra, 1990.

SILVA, Maria do Socorro. As Práticas Pedagógicas das Escolas do Campo: a Escola na Vida e a Vida como Escola. Recife: Centro de Educação, UFPE. Tese de Doutorado, 2009.

SILVA, Maria do Socorro. Da raiz à flor: produção pedagógica dos movimentos sociais e a escola do campo. In: Mônica Castagna Molina. (Org.). Educação do Campo e Pesquisa: questões para reflexão. Brasília: Nead Editora, 1a. ed., 2006.

Recebido: 04/08//2021

Aprovado: 13/12/2021 